\title{
O CONTRATO DE FACTORING INTERNACIONAL NOS ORDENAMENTOS JURÍDICOS BRASILEIRO E PORTUGUÊS E A UNIFORMIZAÇÃO DAS REGRAS APLICÁVEIS A ESTA MODALIDADE CONTRATUAL
}

Denise Kung Bruel ${ }^{1}$

\section{RESUMO}

Com o desenvolvimento das relações comerciais envolvendo partes situadas em países distintos, em decorrência dos efeitos da globalização e da intensificação da interdependência econômica entre os estados, as negociações do contrato de factoring incrementaram-se no âmbito internacional, na década de sessenta, e, a partir de então, adquiriram especial relevância para o Direito Comercial Internacional. Todavia, o contrato de factoring ainda padece de atipicidade legislativa em quase todos os ordenamentos jurídicos - inclusive no Brasil e em Portugal. Diante disso, a Convenção do Unidroit de 1988 sobre o factoring internacional, realizada em Ottawa, bem como a Convenção de Roma de 1980 sobre a lei aplicável às obrigações contratuais merecem destaque pelo papel desepenhado na tentativa de uniformização das regras aplicáveis a esta modalidade contratual no âmbito do comércio internacional.

PALAVRAS-CHAVE: Contrato, Factoring Internacional, Convenção de Ottawa.

\section{NOÇÃO DA FIGURA}

O contrato de factoring ou de cessão financeira é aquele através do qual uma parte - o cliente, aderente ou cedente - cede a outra - o factor ou

\footnotetext{
1 Assessora Jurídica. Mestranda em Direito Internacional pela Faculdade de Direito da Universidade de Lisboa. Especialista em Contratos Empresariais pela Universidade Federal do Paraná. Membro do Núcleo de Pesquisa em Direito Públido do Mercosul (NUPESUL) e do Núcleo de Estudos em Direito Internacional, da Universidade Federal do Paraná.
}

Revista Brasileira de Direito Internacional, Curitiba, v.2, n.2, jul./dez.2005 
cessionário financeiro - os créditos que possui perante um terceiro - o devedor ou debitor - mediante o pagamento de uma remuneração².

Inicialmente, cumpre frisar que o contrato de factoring carece de regulamentação específica na maior parte dos ordenamentos jurídicos ${ }^{3}$, razão pela qual é classificado pela doutrina majoritária como um contrato atípico ${ }^{4}$, porém nominado 5 .

A formação do contrato de factoring baseia-se em um ou mais contratos de cessão de crédito, pois, na realidade, sua essência apresenta traços marcantes e característicos da cessão de crédito $^{6}$, muito embora com ela não possa ser confundida.

Com efeito, a cessão de crédito nada mais é do que uma forma de transmissão de obrigações ou de créditos, que se perfaz através de um contrato celebrado entre o antigo credor e o novo credor, tendo por fundamento o contrato-base.

\footnotetext{
${ }^{2}$ O Supremo Tribunal de Justiça definiu o de factoring como sendo o contrato que "consiste na transferência dos créditos a curto prazo do seu titular (cedente, aderente ou factor) para um factor (cessionário), derivados da venda de produtos ou prestação de serviços a terceiros (devedores cedidos)." (PORTUGAL. Supremo Tribunal de Justiça. Acórdão em acção declarativa ordinária n. 2660/02. "A" SA e "B" - Empresa de Celulose e Papel de Portugal SA. Relator: Araújo Barros. 13 jan. 2005). Já o Decreto-Lei no 171/95, em seu artigo 2ํ, define o contrato de factoring como sendo "a aquisição de créditos a curto prazo, derivados da venda de produtos ou da prestação de serviços, nos mercados interno e externo".

${ }^{3}$ Maria Raquel Aleixo Antunes Rei atenta para a necessidade de consagração legislativa de determinados contratos, dentre os quais inclui o factoring. (REI, Maria Raquel Aleixo Antunes. Do Contrato-Quadro. Lisboa: 1997. 97f. Dissertação (Mestrado em Direito) - Curso de Mestrado em Ciências Jurídicas, Faculdade de Direito da Universidade de Lisboa, p. 75).

${ }^{4}$ Muito embora Maria Helena Brito entenda que o contrato de factoring é um contrato típico, unitário e autônomo, ao afirmar que "em nosso entender é possível considerar, perante o seu núcleo central e mais frequente e atendendo à respectiva função económico-social, que se trata de um contrato socialmente típico". (BRITO, Maria Helena. O factoring internacional e a Convenção do UNIDROIT. Lisboa: Edições Cosmos, 1998, pp. 16/17).

${ }^{5}$ CORDEIRO, António Menezes. Da cessão financeira (Factoring). Lisboa: Lex Edições Jurídicas, 1994, p. 16; DUARTE, Rui Pinto. Notas sobre o contrato de factoring. Novas perspectivas do Direito Comercial. Coimbra: Livraria Almedina, 1988. p. 152; BRITO, Maria Helena. O factoring..., Op. cit., p. 14.

${ }^{6}$ O Supremo Tribunal de Justiça assim já decidiu: “(...) Aliás, sob o aspecto considerado, a diferença de qualificação ocorrida entre as duas instâncias é mero pormenor, uma vez que, como, adiante, se dirá, factoring (qualificação atribuída na Relação) não passa de uma cessão de créditos (qualificação da $1^{\text {a }}$ instância), adaptada ao exercício profissional desta última actividade" (PORTUGAL. Supremo Tribunal de Justiça, Acórdão em acção ordinária n. 2567/03. Relator: Quirino Soares. 04 mar. 2003). No mesmo sentido: CORDEIRO, António Menezes. Da cessão..., Op. cit., p. 23; Manual de Direito Bancário, 2ª ed.. Coimbra: Livraria Almedina, 2001, p. 581; DUARTE, Rui Pinto. Notas sobre..., Op. cit., p. 146; BRITO, Maria Helena. O factoring..., Op. cit., p. 15.
} 
Portanto, nota-se que, num primeiro momento, o contrato de factoring consiste em uma cessão de créditos, muito embora, posteriormente, encontrese revestido de outras particularidades que o distinguem daquela.

Em vista disso, depreende-se que o contrato de factoring reveste a natureza de uma promessa de cessão de créditos ou de uma cessão de créditos futuros ${ }^{7}$, sendo que, em ambos os casos, o factor encontra-se legitimado a exigir o pagamento do devedor mediante o recurso às disposições referentes ao instituto da cessão de créditos ${ }^{8}$.

\subsection{REFERÊNCIA HISTÓRICA}

O contrato de factoring recebeu este nome inspirado na figura do factor, palavra de origem latina que se refere ao comerciante que recebia de Roma a incumbência de desenvolver as atividades econômicas e comerciais em províncias distantes.

A origem do instituto remonta à Antiguidade Oriental, período em que as comunidades mais abastadas economicamente elegiam agentes locais para vender suas mercadorias em nome próprio, em outros domínios, mediante o pagamento de uma remuneração.

O factoring como hoje conhecemos surgiu na época das grandes explorações e colonizações e provém das feitorias atlânticas, que eram grandes depósitos de mercadorias dirigidos pelo feitor, que atuava como uma espécie de agente comercial. Este, ao receber a mercadoria, disponibilizava sua negociação no mercado, cobrava o preço e, ao receber o pagamento, efetuava o repasse do valor ao dono, descontada sua comissão pelos serviços prestados. Por outras vezes, o feitor adquiria mercadorias locais em nome e por conta do dominus, as quais eram enviadas para a metrópole ${ }^{9}$.

\footnotetext{
${ }^{7}$ PORTUGAL. Supremo Tribunal de Justiça. Acórdão em acção ordinária n. 8252/03. Relator: Azevedo Barros. 27 mai. 2004.

${ }^{8}$ Porém, vale ressaltar que a cessão de créditos somente produzirá efeitos em relação ao devedor se ele tiver sido notificado ou, então, desde que ele a aceite. Neste sentido, vide artigo 577 e seguintes do Código Civil Português.

${ }^{9}$ CORDEIRO, António Menezes. Manual de..., Op. cit. p. 613.
}

Revista Brasileira de Direito Internacional, Curitiba, v.2, n.2, jul./dez.2005 
Por conseguinte, a origem do instituto do factoring com a estrutura atual remonta ao período em que o comércio têxtil entre a Inglaterra e suas colônias norte-americanas era muito intenso, onde o factor atuava como representante, consignatário e distribuidor das mercadorias do exportador, sendo também responsável pela gestão e cobrança das faturas.

Logo, nota-se que, inicialmente, o papel do feitor era o de mero intercâmbio entre a metrópole e as colônias, pois, recebia as mercadorias provindas da Europa, armazenava-as em suas instalações, para, posteriormente, revendê-las em nome próprio, mediante o recebimento de uma comissão. Em seguida, suas funções foram aperfeiçoadas e o feitor passou a ser o consultor da qualidade dos produtos, dos preços praticados, da escolha da clientela e, por fim, também era responsável pela garantia do êxito advindo do comércio das mercadorias.

Com a declaração de independência das colônias inglesas, na primeira metade do século XIX, a atividade dos feitores propagou-se nos Estados Unidos através da ampliação de seus serviços mediante a oferta de sua experiência na valoração da situação e na seleção dos clientes, com destaque para as atividades de financiamento e de concessão de crédito, que eram adequadas às necessidades do mercado. Durante este período, todo o comércio de têxteis estava sujeito à atuação dos feitores.

A primeira sociedade de factoring surgiu em 1808, em Nova York ${ }^{10}$, quando um comerciante que assessorava a comercialização dos produtos de pequenas empresas têxteis propôs comprar à vista o que seus clientes vendiam à prazo. A proposta foi aceita e as empresas passaram a transferir ao factor os créditos futuros que tinham para receber, decorrentes de vendas efetuadas a terceiros. Deste modo, o factor passou a assumir as despesas de cobrança, bem como aquelas advindas da falta de realização de pagamento.

No final do século XIX, os Estados Unidos passaram a adotar medidas protecionistas, o que enfraqueceu a atuação das empresas de factoring. Contudo, alternativamente, a solução encontrada foi a oferta dos serviços de aconselhamento comercial e de financiamento prestado pelo factor, que

\footnotetext{
${ }^{10}$ Sob a denominação de Willian Iselin \& Co (CORDEIRO, António Menezes. Manual de..., Op. cit. p. 615).
}

Revista Brasileira de Direito Internacional, Curitiba, v.2, n.2, jul./dez.2005 
culminou na expansão das atividades das sociedades de factoring para outros ramos comerciais, além do setor têxtil.

Com isso, a atuação do factor sofreu alterações, deixando de ser predominantemente comercial, para tornar-se também financeira ${ }^{11}$.

A partir da década de trinta, o factoring norte-americano ressurgiu e novamente adquiriu importância, propiciando a criação de novas empresas, bem como a diversificação do seu objeto ${ }^{12}$. Ademais, durante este período, começou a apresentar suas características atuais.

Porém, na década de sessenta, o contrato de factoring experimentou 0 período de maior prosperidade, pois foi aí que ocorreu sua internacionalização - em decorrência do desenvolvimento econômico norte-americano -, bem como sua introdução na Europa ${ }^{13}$, onde se expandiu rapidamente e foi muito bem sucedido, passando a abranger setores e produtos muito mais amplos do que nos Estados Unidos.

Como o mercado interno norte-americano sempre se manteve forte e inflexível, não houve interesse por parte deste país, nem tampouco necessidade, no desenvolvimento do contrato de factoring no âmbito internacional.

Ocorre que, em consequência da intensificação das relações comerciais entre os países, bem como do comércio internacional, o contrato de factoring desenvolveu-se muito, especialmente na Europa, razão pela qual passou a ser objeto de respaldo legal em alguns países ${ }^{14}$. No entanto, esta modalidade contratual ainda carece de legislação ou ato regulamentador específico no Brasil e em Portugal.

\footnotetext{
${ }^{11}$ Atualmente, há quem considere esta como sendo a principal função exercida pelo factor. (BRITO, Maria Helena, O factoring..., Op. cit., p. 11; CORDEIRO, António Menezes, Da cessão..., Op. cit., p. ).

${ }^{12}$ Muito embora ainda houvesse uma predominância do setor têxtil nas operações de factoring nos Estados Unidos.

${ }^{13} \mathrm{O}$ factoring desenvolveu-se principalmente na Itália. E, muito embora este país tenha sofrido algumas restrições de crédito, ao contrário do que se possa imaginar, isso acabou por fortalecer as sociedades de factoring, em razão do reconhecimento das inúmeras vantagens proporcionadas pelos serviços disponibilizados.

${ }_{14}$ Dentre os quais destacam-se a França, a Holanda, a Bélgica, a Suíça e a Espanha. Nos Estados Unidos, o contrato de factoring é regulado pelo Uniform Commercial Code. (STRENGER, Irineu. Contratos Internacionais do Comércio, 4 ed.. São Paulo: LTR, 2003.
}

Revista Brasileira de Direito Internacional, Curitiba, v.2, n.2, jul./dez.2005 
O Instituto Internacional para Unificação do Direito Privado - UNIDROIT - estudou os aspectos do contrato de factoring pela primeira vez na década de setenta e, em 1988, organizou a Convenção de Ottawa sobre o factoring internacional, cujo principal objetivo era delimitar os contornos desta modalidade contratual.

A Convenção contou com a participação de cinquenta e cinco países, dos quais quatorze a assinaram, sendo que apenas a França, a Itália e a Nigéria a ratificaram. Atualmente a Convenção vigora nestes três países, na Hungria, na Letônia e na Alemanha ${ }^{15}$.

Atualmente, o grau de consolidação alcançado pelo contrato de factoring resulta do interesse que esta modalidade contratual proporciona ao comércio, bem como das vantagens decorrentes de sua utilização.

Outrossim, sua difusão também é devida ao contexto econômico e comercial da União Européia - em que as relações comerciais internacionais são muito intensas -, assim como às vantagens que proporciona para as pequenas e médias empresas no desenvolvimento de suas atividades de exportação em outros mercados - em igualdade de condições com as grandes empresas locais -, e na expansão de seus recursos.

Desta forma, não é de se estranhar que, atualmente, as contratações envolvendo o factoring no âmbito europeu já tenham ultrapassado o volume de negociações norte-americano.

O factoring somente foi introduzido no Brasil no início da década de oitenta, não sendo objeto de legislação específica, razão pela qual se encontra amparado no Código Civil Brasileiro ${ }^{16}$ e em legislações esparsas ${ }^{17}$.

\footnotetext{
${ }^{15}$ A Convenção de Ottawa entrou em vigor na França, Itália, e Nigéria, em 01/05/95; na Hungria, em 01/12/96; na Letônia, em 01/03/98 e na Alemanha, em 01/12/98. Cf. informações obtidas junto ao site do Unidroit. Disponível em: <www.unidroit.org $>$. Acesso em jan., fev., mar., jun., ago. 2005.

${ }_{17}^{16}$ Lei n. 10.646 de 10 de janeiro de 2002.

17 Lei n. 9249 de 26 de dezembro de 1995; Lei n. 5474 de 18 de julho de 1968; Lei n. 8981 de 20 de janeiro de 1995; Lei n. 9430 de 27 de dezembro de 1996 e Resolução do Conselho Monetário n. 2144, de 22 de fevereiro de 1995.

Cumpre asseverar que, no Direito Brasileiro, as sociedades de factoring não necessitam de autorização do Banco Central para seu funcionamento, pois não constituem instituições financeiras. No entanto, suas atividades são fiscalizadas pela Associação Nacional das Sociedades de Fomento Mercantil - ANFAC. Neste sentido, o Superior Tribunal de Justiça já decidiu: "(...)I - "Factoring" não se confunde com Instituição Financeira, sendo vedada à empresa de "factoring" a prática de qualquer operação com as características privativas das
}

Revista Brasileira de Direito Internacional, Curitiba, v.2, n.2, jul./dez.2005 
O contrato de factoring encontra-se previsto no ordenamento jurídico português nos Decretos-Lei oㅡ 298/92, de 31 de dezembro e 171/95 de 18 de julho, que foi alterado pelo Decreto-Lei no 186/02, de 21 de agosto, sendo que o exercício desta atividade é restrito aos bancos e sociedades de factoring, que se sujeitam a normas rigorosas quando da sua constituição e encontram-se sob fiscalização do Banco Central.

\section{DEFINIÇÃO DO CONTRATO DE FACTORING INTERNACIONAL}

A definição do contrato de factoring internacional não constitui uma tarefa simples, por se tratar de uma figura cuja aplicabilidade, além de ser muito ampla, ainda encontra-se repleta de particularidades, dentre as quais a mais relevante é a ausência de tipificação legal.

Por esta razão, nota-se que a Convenção de Ottawa evitou a conceituação pormenorizada do contrato de factoring, a fim de evitar maiores delongas, bem como a imposição de restrições quanto ao seu âmbito de aplicação por mero rigorismo formal ${ }^{18}$.

O artigo $1^{\circ}$ da Convenção Unidroit sobre factoring internacional define ${ }^{19}$ esta modalidade contratual como sendo o contrato celebrado entre duas partes, o fornecedor e o factor ou cessionário financeiro ${ }^{20}$.

\footnotetext{
instituições financeiras autorizadas a funcionar pelo Banco Central.(...)". (BRASIL. Superior Tribunal de Justiça. "Habeas corpus". Crime societário. Falta de justa causa e inépcia da denúncia. Atividades privativas de instituição financeira. "Factoring". Individualização da conduta. Habeas corpus indeferido. Acórdão em habeas corpus no 7463-PR. Relator: Ministro Félix Fischer. DJ, 22 fev. 1999).

${ }_{18}$ Desta forma, a inexistência de descrição do contrato, bem como de sua delimitação minuciosa, possibilitam a abrangência das várias modalidades contratuais existentes.

${ }^{19}$ JIMÉNEZ, Maria Angela Sanches assevera que a Convenção "partiu de uma definição por ser necessária para regulamentar de maneira uniforme o contrato, mas se trata de um mínimo de exigibilidade, de forma que não impeça a possível adesão de qualquer país por uma questão de divergência com seu próprio conceito sobre esta figura contratual". (JIMÉNEZ, Maria Ángeles Sanches. El contrato..., Op. cit., p. ).

${ }^{20}$ Numa tradução aproximada, o artigo $1^{\circ} \stackrel{0}{ }$ n. 2, assim dispõe:

"Para os propósitos desta Convenção, contrato de factoring é o contrato celebrado entre duas partes (o fornecedor) e outra parte (o factor) em virtude do qual:

(a) o fornecedor pode ou deve ceder ao factor créditos nascidos de contratos de compra e venda de mercadorias concluídos entre o fornecedor e seus clientes (devedores), com exclusão dos que se referem a mercadorias adquiridas a título principal para uso pessoal, familiar ou doméstico;

(b) o factor deve desenvolver pelo menos duas das seguintes funções:
}

Revista Brasileira de Direito Internacional, Curitiba, v.2, n.2, jul./dez.2005 
Contudo, diante da impossibilidade de individualização das funções a serem prestadas pelo factor, a Convenção condicionou a sua aplicação ao exercício, pelo factor, de pelo menos duas das funções elencadas em seu artigo $1^{\circ}$, n. 2.

$\mathrm{Na}$ verdade, o contrato de factoring internacional está centrado nas cessões de créditos que surgem dos contratos de compra e venda de mercadorias e de prestação de serviços ${ }^{21}$ e aplica-se somente aos créditos comerciais, pois verifica-se que a Convenção excluiu expressamente os créditos destinados para o uso pessoal, familiar ou doméstico dos compradores.

Quanto à notificação da cessão de créditos, a Convenção aplica-se apenas às operações de factoring em que a notificação esteja prevista ${ }^{22}$.

Porém, em alguns casos, o contrato de factoring pode conter uma cláusula de exclusividade, através da qual o fornecedor fica obrigado a ceder todos os seus créditos ao factor ${ }^{23}$.

Por outro lado, a definição do contrato de factoring contida na Convenção de Ottawa refere-se genericamente ao factor, pois não há a distinção entre o export-factor e o import-factor.

Assim sendo, nota-se que o sistema de dois factors não constitui o objeto exclusivo de regulamentação pela referida Convenção, que também se aplica às demais modalidades de contrato de factoring internacional.

Portanto, conclui-se que a estruturação do contrato de factoring tem sido elaborada fundamentalmente pelos entendimentos doutrinário e jurisprudencial.

\footnotetext{
- financiamento ao fornecedor, incluindo a concessão de empréstimos ou pagamentos antecipados;

- manutenção das contas referentes aos créditos;

- cobrança dos créditos;

- proteção contra a falta de pagamento dos devedores;

(c) A cessão de créditos deve ser notificada aos devedores."

${ }_{21}$ Para 0 artigo $1, n$. 3 , as referências a mercadorias e compra e venda de mercadorias também incluem serviços e prestação de serviços.

${ }^{22}$ A exigência de notificação da cessão de créditos está prevista no art. 1 , n. 4, da Convenção de Ottawa, e deve ser efetuada por escrito, a fim de garantir maior certeza, bem como evitar litígios quanto à sua prova.

${ }^{23}$ Mas, vale ressaltar que a cláusula de exclusividade está sujeita à estipulação previamente estabelecida entre as partes contratantes.
}

Revista Brasileira de Direito Internacional, Curitiba, v.2, n.2, jul./dez.2005 


\subsection{DELIMITAÇÃO DO CONTRATO DE FACTORING} INTERNACIONAL

O pressuposto básico para que um contrato de factoring possa ser considerado internacional consiste na existência de uma operação realizada entre uma empresa exportadora - credora - e uma empresa importadora devedora - situadas em países distintos. Consequentemente, isso implica na existência de várias barreiras quanto à legislação, língua e costumes envolvidos no contrato $^{24}$. Todavia, tais barreiras, que para 0 exportador acarretam uma série de dificuldades e riscos, despertam o seu interesse pela escolha de uma sociedade de factoring, que exerce múltiplas funções na prestação destes serviços em diversos países.

Desta feita, verifica-se que o caráter internacional do contrato de factoring resulta essencialmente da internacionalidade dos créditos cedidos ${ }^{25}$.

Por outro lado, nota-se que o contrato de factoring considera-se internacional quando tem por objeto a cessão de créditos decorrentes de um contrato internacional de compra e venda de mercadorias ou de prestação de serviços. Vale dizer, o que define o caráter internacional do contrato de factoring é o contrato de compra e venda de mercadorias ou de prestação de serviços ao qual ele se refere.

Por conseguinte, resta evidente que, tanto o país de origem do import factor, quanto do export factor são determinantes do mecanismo que irá reger o contrato de factoring internacional, muito embora o país em que a operação de exportação se originou seja o responsável pela demarcação do caráter internacional do contrato. Este é o critério utilizado pela Convenção de Ottawa sobre o factoring internacional, segundo o qual, vale ressaltar, a internacionalidade do contrato decorre do caráter internacional dos créditos cedidos.

\footnotetext{
${ }^{24}$ JIMÉNEZ, Maria Ángeles Sanches. El contrato de Factoring. In CARAVACA, Alfonso L. Calvo; GÁNDARA, Luis Fernández de la. Contratos Internacionales, Madrid: Tecnos, 1997, p. 982.

${ }^{25}$ A Convenção de Ottawa assenta-se nesta premissa. Maria Helena Brito afirma que o contrato de factoring internacional caracteriza-se pela transcendência do âmbito de um estado. (BRITO, Maria Helena. O factoring..., Op. cit., p. 23).
}

Revista Brasileira de Direito Internacional, Curitiba, v.2, n.2, jul./dez.2005 
Assim, considerando as inúmeras diferenças existentes entre o contrato de factoring interno e o contrato de factoring internacional, esta é a razão pela qual a distinção adquire relevância para o presente estudo.

No factoring internacional, a relação entre os sujeitos é quadrangular, pois envolve o exportador, seus devedores, o export-factor e o import-factor. Já no factoring interno, a relação entre as partes é triangular e envolve o fornecedor, o factor e os devedores.

Por outro lado, pode-se afirmar que o factoring internacional é um contrato mais complexo, pois envolve partes situadas em países distintos, o que acarreta inúmeras dificuldades a serem superadas pelas partes do que no contrato de factoring interno.

Neste sentido, nota-se que, em razão da diversidade de regulação dos ordenamentos jurídicos com os quais se encontra em contato, o contrato de factoring internacional esbarra em problemas cambiais, implica em maiores riscos de insolvabilidade por parte dos compradores e, por fim, está sujeito a diversas formalidades burocráticas.

Além disso, por não haver uniformização do direito aplicável aos contratos de factoring internacional, aplica-se o direito escolhido pelas partes e, na falta deste, o direito internacional privado do país em que as questões forem suscitadas.

2.2 MODALIDADES DO CONTRATO DE FACTORING INTERNACIONAL

\subsubsection{O Import-export Factoring ou Sistema de Dois Factors}

O import-export factoring ou sistema de dois factors - two factors system - é aquele em que ocorre a cessão, por um exportador, de créditos sobre devedores estabelecidos em outro país, a uma sociedade de factoring estabelecida no seu próprio país - o export-factor. Este, por sua vez, ao invés de efetuar diretamente a cobrança dos créditos sobre devedores estabelecidos 
fora do seu país, contrata uma sociedade de factoring do país do devedor - o import-factor -, que se incumbe de fazê-lo.

Em vista disso, nota-se que a empresa exportadora recorre a uma sociedade de factoring situada em seu país - o export-factor - para concluir um contrato. O export-factor, por sua vez, solicita a um factor do país do importador - o import factor - informações a respeito do comprador, a fim de verificar as condições de sua solvência. E, caso o impor-factor conclua pela solvência positiva do devedor, comunica sua aprovação ao export-factor, que a repassa ao cliente. A partir deste momento, a exportação está apta a ser realizada com segurança.

Assim, depreende-se que o import-export factoring pressupõe a existência de dois acordos distintos, mas conexos entre si: um celebrado entre a empresa exportadora e o export-factor e outro entre o export-factor e o import-factor $^{26}$.

Nesta modalidade contratual, o export-factor antecipa ao exportador a importância dos créditos adquiridos, com a particularidade de que o importfactor assume o risco da cobrança dos créditos, gere a carteira de devedores e procede à cobrança dos cráditos mediante o pagamento de uma comissão.

Com isso, pode-se afirmar que o sistema de dois factors implica num incremento do papel exercido pela atuação dos factors intervenientes, que passam a ter desdobradas entre si as funções que, no factoring interno, são realizadas por um único factor. Consequentemente, isso resulta em uma maior complexidade em relação às partes e às relações existentes entre elas.

$\mathrm{Na}$ realidade, verifica-se que a cessão de créditos propriamente dita ocorre no acordo firmado entre a empresa exportadora e o export factor, pois este contrato não difere muito de um contrato de factoring interno, exceto pela influência que recebe das cláusulas contidas no acordo inter factors. Porém, perante o cliente, o export-factor possui exatamente as mesmas funções que no factoring interno.

O acordo inter-factors, por sua vez, normalmente sujeita-se às regras contidas nos acordos de mútua colaboração vigentes nas Cadeias

\footnotetext{
${ }^{26}$ Ressalte-se que um novo contrato de factoring é celebrado entre o export-factor e o importfactor, também chamado de de factoring sucessivo ou refactoring.
}

Revista Brasileira de Direito Internacional, Curitiba, v.2, n.2, jul./dez.2005 
Internacionais de Factoring, que contém as regras que regulam o seu funcionamento, inclusive na resolução de conflitos, que podem ser submetidos à arbitragem.

Dentre as cláusulas mais relevantes contidas nos acordos entre o export-factor e o import-factor, destacam-se:

a) a obrigação de transmitir mutuamente todos os créditos que versem sobre devedores dos respectivos países (cláusula de exclusividade);

b) a garantia de existência dos créditos cedidos;

c) o critério de fixação da comissão de correspondência recíproca;

d) o modo de repartição das despesas;

e) a forma de designação de árbitro para solução de uma eventual controvérsia ${ }^{27}$.

Portanto, o sistema de dois factors é a modalidade de contrato de factoring mais praticada no comércio internacional, tendo como principal vantagem o fato de que, como o import-factor encontra-se estabelecido no mesmo país do devedor, conhece o direito e a prática negocial deste país, fala a mesma língua e possui melhores condições e mais facilidade de acesso ao devedor.

Em contrapartida, as desvantagens resumem-se na possibilidade de ocorrência de atrasos na realização da operação, bem como no aumento dos custos, especialmente nos casos em que há a atuação de dois factors independentes.

Contudo, a fim de evitar estes inconvenientes, o export-factor pode recorrer às suas sucursais em outros países ou optar pela integração em uma Cadeia Internacional de Factoring.

\subsubsection{Direct Import Factoring}

O direct import factoring consiste no contrato de factoring concluído diretamente entre a empresa exportadora e o factor do país da empresa importadora - o import-factor.

\footnotetext{
${ }^{27}$ Que, habitualmente, é feita através de indicação procedida pela Câmara de Comércio Internacional (CCl). Disponível em: <http://www.iccwbo.org/>. Acesso em: jun., ago. 2005.
}

Revista Brasileira de Direito Internacional, Curitiba, v.2, n.2, jul./dez.2005 
Desta feita, o exportador cede seus créditos a uma sociedade de factoring estabelecida no país do importador e o factor, por sua vez, apenas transmite os fundos ao credor depois de cobrá-los do devedor.

Nesta modalidade contratual, há a intervenção de apenas um factor e, portanto, uma estrutura triangular, na qual este presta apenas a função de cobrança.

\subsubsection{Direct Export Factoring}

No direct export factoring, o credor cede seus créditos a uma sociedade de factoring estabelecida no seu país - o export-factor. O factor, por sua vez, desempenha todas as funções tradicionais e trata diretamente com 0 devedor, razão pela qual deve conhecer a língua, os costumes e o direito do país do devedor, podendo vir a ter de deslocar-se ou, então, designar um representante residente nesse país.

Esta modalidade de contrato constitui uma alternativa ao sistema de dois factors, pois é operado diretamente pelo export-factor contra o devedor, sem que haja a necessidade de intervenção de um import-factor, muito embora, ainda assim, as vantagens iniciais do direct export factoring não superem os inconvenientes encontrados no import-export factoring.

\section{LEI APLICÁVEL}

\subsection{A CONVENÇÃO DE ROMA DE 1980 SOBRE A LEI APLICÀVEL ÀS OBRIGAÇÕES CONTRATUAIS}

Com a intensificação dos contratos no âmbito do comércio internacional, o que, muitas vezes, implica, no envolvimento de dois ou mais ordenamentos jurídicos com soluções distintas para o conflito, restou evidente a necessidade de unificação da legislação a ser aplicada aos contratos internacionais.

Revista Brasileira de Direito Internacional, Curitiba, v.2, n.2, jul./dez.2005 
Neste sentido, a Convenção de Roma de 1980 sobre a lei aplicável às obrigações contratuais foi firmada pelos países membros da Comunidades Européia a fim de unificar a matéria de conflitos referente às obrigações contratuais.

Para que se possa identificar o direito aplicável ao contrato de factoring internacional, inicialmente, faz-se necessário estabelecer o direito nacional a ser aplicado ao contrato de factoring.

Com efeito, o critério fundamental para definir o direito a ser aplicado no caso de ocorrência de eventuais conflitos baseia-se na escolha das partes, como corolário do princípio da autonomia da vontade, que se afigura fundamental para a regulação das obrigações contratuais ${ }^{28}$. E, como critério supletivo, caso as partes não tenham escolhido o direito competente para reger o contrato, a lei aplicável será aquela com a qual o contrato apresente a conexão mais estreita ${ }^{29}$.

Desta forma, normalmente a lei aplicável será a do país em que se situa a sede ou estabelecimento do factor, cuja atribuição constitui a prestação característica do contrato de factoring ${ }^{30}$, e, consequentemente, a conexão mais estreita.

Todavia, a solução para que se possa determinar a lei aplicável ao contrato de factoring pode consistir, ainda, naquela prevista no artigo $12^{\circ}$ da Convenção de Roma, que regula a lei aplicável ao contrato de cessão de créditos.

Em vista disso, nota-se que a disparidade de regulamentação existente entre os ordenamentos jurídicos tem sido assinalada como a principal causa que impede a difusão do factoring no âmbito do internacional, apesar das vantagens que apresenta para as partes contratantes.

\footnotetext{
${ }^{28}$ Isso é o que se depreende do artigo $3^{\circ}$ da Convenção de Roma.

${ }^{29}$ Este é o critério adotado pelo artigo $4^{\circ}$ da Convenção de Roma.

Nota-se que, no caso do factoring, o contrato apresenta conexão mais estreita com o país onde será realizada a prestação característica - vale dizer, a lei do país em que a parte que está obrigada a realizar tal prestação ou tinha sua residência habitual no momento da contratação.

${ }^{30}$ (BRITO, Maria Helena. O factoring..., Op. cit., p. 28).
}

Revista Brasileira de Direito Internacional, Curitiba, v.2, n.2, jul./dez.2005 
Por isso, é essencial que as partes envolvidas conheçam previamente o ordenamento jurídico ao qual a norma material deverá ajustar-se a fim de que o contrato possa ser considerado válido.

Não obstante, a determinação da lei aplicável torna-se difícil quando o contrato está em contato com legislações que contenham normas de conflito distintas e que possam conduzir à aplicação de ordenamentos jurídicos diferentes, pois, em decorrência disso, o contrato poderia vir a ser submetido a uma regulamentação contraditória.

Da mesma forma, a disparidade das normas de conflito reflete na segurança jurídica - que se afigura imprescindível para as relações contratuais comerciais -, e, portanto, pode consistir em um empecilho para o desenvolvimento do contrato de factoring internacional.

Assim, resta evidente a necessidade de uniformização das normas de conflito entre os diferentes estados no âmbito do comércio internacional, a fim de que a lei aplicável ao contrato de factoring seja a mesma, com independência do tribunal competente para conhecer da causa. Certamente isso garantiria a segurança jurídica necessária para que as partes pudessem conhecer prévia e detalhadamente as normas materiais às quais o contrato deveria se ajustar.

Esta unificação já ocorre no âmbito comunitário, através da Convenção de Roma de 1980, que estabeleceu regras uniformes em matéria de lei aplicável às obrigações contratuais na União Europeia ${ }^{31}$.

Com efeito, verifica-se que a disparidade entre as normas materiais existentes nos diferentes ordenamentos jurídicos dos países pode ser determinante de uma diferente posição jurídica das partes envolvidas no contrato de factoring, justamente em razão da lei que vier a ser aplicada.

Em relação ao factor, torna-se complexo o fato de que deva operar de modo distinto se o contrato de factoring tiver de se ajustar a normas materiais distintas em razão da lei aplicável, pois pode atuar em nível internacional como export-factor ou import-factor não só de empresas diferentes, mas também de

\footnotetext{
${ }^{31}$ A Convenção de Roma aplica-se às obrigações contratuais nas situações que impliquem um conflito de leis, ainda que a lei designada possa vir a ser a de um Estado não contratante.
}

Revista Brasileira de Direito Internacional, Curitiba, v.2, n.2, jul./dez.2005 
uma mesma empresa, tanto no que se refere às suas exportações quanto às suas importações.

Da mesma forma, o devedor também pode ser diretamente afetado pela disparidade de legislação entre os diferentes ordenamentos jurídicos, pois, em contratos iguais, sua posição jurídica pode vir a ser diferente, dependendo da lei do país aplicável ao contrato.

Por conseguinte, no âmbito do comércio internacional, a uniformidade normativa afigura-se imprescindível para assegurar a aplicação de condições iguais, bem como para estabelecer um equilíbrio entre os interesses das partes envolvidas no contrato de factoring.

Este foi justamente um dos principais objetivos que motivou a realização da Convenção de Ottawa sobre factoring internacional, elaborada pelo Unidroit.

Todavia, a Convenção de Ottawa não obteve êxito na unificação do direito aplicável, pois nem todos as aspectos do contrato de factoring puderam ser harmonizados, dada sua pretensão de ter uma vasta abrangência, a fim de possibilitar a ratificação pelo maior número de países, o que, a despeito disso, não foi possível, em razão da imposição de restrições por parte dos mesmos.

\subsubsection{A Relação Entre o Cedente e o Cessionário}

Para que se possa determinar a lei aplicável às relações entre o cedente e o cessionário, inicialmente, faz-se necessário identificar a ordem jurídica nacional competente para reger o contrato de factoring.

No direito internacional privado português, a determinação da legislação aplicável implica no recurso à Convenção de Roma de 1980 sobre a lei aplicável às obrigações contratuais.

Com efeito, conforme anteriormente asseverado, o artigo $3^{\circ}$ da Convenção de Roma determina a observância ao princípio da autonomia da 
vontade, ao estabelecer que o contrato será regido pelo direito designado pelas partes $^{32}$.

Por outro lado, caso as partes não tenham designado o direito competente, aplica-se, então, o artigo $4^{\stackrel{0}{ }}$, n. 1 , que estabelece que o contrato será regido pelo direito do país com o qual o contrato apresenta a conexão mais estreita ${ }^{33}$.

Diante disso, a Convenção de Roma estabeleceu que se aplica o direito escolhido pelas partes, em observância ao princípio da autonomia da vontade. E, na falta deste, aplica-se o direito do país com o qual o contrato apresenta a conexão mais estreita, o qual, no contrato de factoring, consiste na lei do país onde se situa a sede ou o estabelecimento principal do factor $^{34}$.

Ocorre que o instrumento jurídico do contrato de factoring é a cessão de créditos, razão pela qual o regime do contrato é o da cessão de créditos, do ponto de vista de solução de conflitos. Neste caso, a lei aplicável é a do contrato que estabelece a ligação entre o cedente e o cessionário, inclusive no que diz respeito aos créditos futuros ${ }^{35}$. No entanto, o entendimento doutrinário encontra-se dividido, pois há quem considere como aplicável a lei reguladora do crédito cedido ${ }^{36}$.

\footnotetext{
${ }^{32}$ Artigo 3․ 1 . O contrato rege-se pela lei escolhida pelas Partes. Esta escolha deve ser expressa ou resultar de modo inequívoco das disposições do contrato ou das circunstâncias da causa. Mediante esta escolha, as Partes podem designar a lei aplicável à totalidade ou apenas a uma parte do contrato.

${ }_{33}$ Artigo $4^{\circ}$. 1. Quando a lei aplicável ao contrato não tiver sido escolhida nos termos do artigo $3 .^{\circ}$, o contrato é regulado pela lei do país com o qual apresente uma conexão mais estreita. Todavia, se uma parte do contrato for separável do resto do contrato e apresentar uma conexão mais estreita com um outro país, a essa parte poderá aplicarse, a título excepcional, a lei desse outro país.

${ }^{34}$ Artigo 4. 2. Sem prejuízo do disposto no $n .{ }^{\circ} 5$, presume-se que o contrato apresenta uma conexão mais estreita com o país onde a Parte que está obrigada a fornecer a prestação característica do contrato tem, no momento da celebração do contrato, a sua residência habitual ou, se se tratar de uma sociedade, associação ou pessoa colectiva, a sua administração central. Todavia, se o contrato for celebrado no exercício da actividade económica ou profissional dessa Parte, o país a considerar será aquele em que se situa o seu estabelecimento principal ou, se, nos termos do contrato, a prestação deverá ser fornecida por estabelecimento diverso do estabelecimento principal, o da situação desse estabelecimento.

${ }^{35}$ Artigo. 12. 1. As obrigações entre o cedente e o cessionário de um crédito são reguladas pela lei que, por força da presente Convenção, for aplicável ao contrato que os liga.

${ }^{36}$ Artigo 12. 2. A lei que regula o crédito cedido determina a natureza cedível deste, as relações entre o cessionário e o devedor, as condições de oponibilidade da cessão ao devedor e a natureza liberatória da prestação feita pelo devedor.
} 
Contudo, em que pese ambos os posicionamentos doutrinários, a aplicação da lei reguladora do contrato de cessão de créditos futuros afigura-se mais coerente, por se referir ao objeto do contrato. Além disso, também pode ser considerada como pressuposto de validade do contrato de cessão de créditos.

Em contrapartida, a lei reguladora do crédito cedido, parece ser mais adequada se for aplicada à eficácia da cessão de créditos em relação a terceiros - quais sejam, os credores do cedente -, a fim de evitar incompatibilidades na aplicação de leis diferentes à eficácia da cessão entre o cessionário e o devedor e em relação a terceiros e, concomitantemente, atribuir a competência a uma das leis designadas pela Convenção de Roma em matéria de cessão de créditos. Com isso, a possibilidade de aplicação de ordenamentos jurídicos distintos resta devidamente solucionada.

\subsubsection{A Relação Entre o Devedor e o Cessionário}

Regra geral, no contrato de factoring, a relação entre o fornecedor e o devedor advém de um contrato de compra e venda de mercadorias ou de prestação de serviços. Em decorrência disso, o contrato base será regido pelas normas contidas nas Convenções Internacionais de direito material a que o estado encontra-se vinculado.

Neste sentido, a Convenção de Viena de 1980 sobre Compra e Venda de Mercadorias afigura-se fundamental no que se refere aos contratos de compra e venda internacional de mercadorias, por força do disposto em seu artigo 1, n. 1, alínea "b", muito embora o Brasil e Portugal não sejam Estados signatários ${ }^{37}$.

\footnotetext{
${ }^{37}$ Porém, a despeito disso, a Convenção de Viena possui extrema relevância para ambos os países. Com efeito, a Convenção aplica-se aos contratos de compra e venda de mercadorias celebrados entre partes que tenham o seu estabelecimento em Estados contratantes (art. 10, I, a), hipótese que não atinge tanto o Brasil quanto Portugal, mas também regula aqueles contratos aos quais se aplicar, pelas regras do direito internacional, a lei de um Estado contratante (art. 1이 I, b).
}

Revista Brasileira de Direito Internacional, Curitiba, v.2, n.2, jul./dez.2005 
Desta forma, não sendo aplicável um direito material uniforme, aplicase o ordenamento jurídico considerado competente pelas normas de direito internacional privado vigentes no foro.

No caso do contrato de factoring, normalmente a lei aplicável ao crédito cedido é a mesma que regula a posição jurídica do devedor ${ }^{38}$. Esta lei também se aplica para determinar a possibilidade de cessões sucessivas de crédito por parte do factor ${ }^{39}$.

A Convenção de Ottawa efetuou a distinção entre a lei aplicável à cessão de crédito e a lei aplicável ao seu objeto, qual seja, o crédito cedido.

Portanto, depreende-se que a intenção do legislador foi justamente a de resguardar a posição jurídica do devedor do crédito, pois, em relação à determinação da lei que rege a cessão, o devedor apresenta-se como um terceiro e, em decorrência disso, não pode por ela ser afetado, nem tampouco ter sua situação agravada.

\subsubsection{A Relação Entre o Export-factor e o Import-factor}

Ao analisar a Convenção de Ottawa sobre o factoring internacional, verifica-se que, em momento algum, o legislador preocupou-se em fazer a distinção entre o import-factor e o export-factor, nem tampouco à lei aplicável à relação existente entre eles.

Ocorre que, normalmente, a relação inter-factors contém uma cláusula de arbitragem que remete a resolução de eventuais litígios à Câmara de Comércio Internacional $(\mathrm{CCl})$ ou, quando não, sua submissão às regras contidas nos Códigos de Conduta adotados pelas Cadeias Internacionais de Factoring aos quais os factors estiverem integrados.

É o caso do Code of International Factoring Customs, adotado pela Factors Chain International (FCl), que regula as operações de factoring do sistema de dois factors.

\footnotetext{
${ }^{38}$ Assim como suas relações com o factor, as condições de oposição da cessão ao devedor e o caráter liberatório da prestação do devedor.

${ }^{39}$ Art. 12, n. 2, da Convenção de Roma.
}

Revista Brasileira de Direito Internacional, Curitiba, v.2, n.2, jul./dez.2005 
As regras dispostas neste código regulam a assunção do risco do crédito, a obrigação de pagamento, as garantias e as obrigações das partes, a indenização, os prazos e a antecipação de pagamentos, remetendo a resolução de litígios à arbitragem.

Todavia, na ausência de previsão ou remissão a estes códigos de conduta, a solução para determinação da lei aplicável à relação inter factors encontra-se na Convenção de Roma.

Nota-se que, na relação entre o export-factor e o import-factor, este é quem realiza a prestação característica, pois assume o risco pela cobrança dos créditos, gere a certeira de devedores e procede a cobrança dos créditos adquiridos.

Assim sendo, não havendo outra lei escolhida pelas partes, depreendese que o contrato inter-factors deve ser regido pelo ordenamento jurídico do país em que se situa a sede ou estabelecimento principal do import-factor.

Por conseguinte, faz-se mister atentar para o fato de que, no contrato de factoring internacional, as regras de conflito podem conduzir à aplicação de diferentes ordenamentos jurídicos às relações entre o fornecedor e o factor, entre o fornecedor e o seu devedor e entre o export-factor e o import-factor, em razão da complexidade das relações entre as partes envolvidas nesta modalidade contratual ${ }^{40}$.

\subsection{A CONVENÇÃO UNIDROIT SOBRE O FACTORING} INTERNACIONAL

\subsubsection{Introdução e Objetivos}

A Convenção do Unidroit sobre o factoring internacional foi realizada em Ottawa, entre 09 e 28 de maio de 1988, tendo como principal objetivo

\footnotetext{
${ }^{40}$ No entanto, Luís Miguel Vasconcelos assevera que "tanto o contrato donde o crédito emerge (o contrato de compra e venda ou de prestação de serviços internacional), como o contrato pelo qual se cede o crédito ao factor são, neste caso, regulados pela mesma lei, isto é, a lei do país do vendedor ou do prestador de serviços e do factor exportador". (VASCONCELOS, Luís Miguel D. P. Pestana de. Dos contratos de cessão financeira (Factoring). In Boletim da Faculdade de Direito - Universidade de Coimbra. Coimbra: Coimbra Editora, 1999, p. ).
}

Revista Brasileira de Direito Internacional, Curitiba, v.2, n.2, jul./dez.2005 
facilitar o desenvolvimento desta modalidade contratual no comércio internacional ${ }^{41}$.

A Convenção não se presta nem pretende regular todos os aspectos do contrato de factoring internacional, mas especialmente aqueles que se afiguram essenciais e mais problemáticos e que, a despeito destas dificuldades, são passíveis de unificação nos diversos ordenamentos jurídicos.

Com efeito, verifica-se que a elaboração de um projeto mais ambicioso poderia esbarrar em obstáculos impostos para a sua aceitação por um número significativo de países, o que impediria o cumprimento do seu objetivo.

Ocorre que, se, por um lado, a Convenção tem um alcance limitado, por não tratar de todos os aspectos do contrato de factoring - tendo enfatizado especialmente a cessão de créditos entre as partes e os seus efeitos perante terceiros -, por outro, o legislador confiou a complementação das lacunas existentes à vontade das partes contratantes, em observância ao princípio da autonomia da vontade.

Além disso, não se pode negar que a Convenção de Ottawa foi fortemente influenciada pela Convenção de Viena de 1980 sobre Compra e Venda de Mercadorias, com a qual guarda estreita relação.

O objetivo fundamental da Convenção de Ottawa consiste na unificação do regime aplicável aos contratos de factoring internacional, pois se trata de uma convenção de direito material uniforme que procura prevenir e evitar os problemas de conflitos de lei referentes a esta modalidade de contrato.

Todavia, por regular apenas alguns aspectos do contrato de factoring internacional, a Convenção ainda prescinde das normas de conflito dos países das partes envolvidas para poder determinar a lei aplicável ao caso concreto ${ }^{42}$, a exemplo da Convenção de Roma, conforme restou anteriormente demonstrado.

${ }^{41}$ CALERO, Fernando Sánchez. El Contrato de Factoring em el Convenio Internacional de 1988. In Jornadas sobre factoring. Madrid: Servicio de Publicaciones - Facultad de Derecho, 1992, p. 21.

${ }^{42}$ Isso é o que se depreende da redação do artigo 4ำ n. 2, da Convenção de Ottawa.

Revista Brasileira de Direito Internacional, Curitiba, v.2, n.2, jul./dez.2005 
3.2.2 Necessidade de Delimitação do Caráter Internacional do Contrato de Factoring Para Sua Aplicabilidade

Inicialmente, cumpre mencionar que, por ter a Convenção de Ottawa o seu âmbito de aplicação restrito aos contratos de factoring internacional, faz-se necessário que os créditos cedidos na base da operação do contrato de factoring sejam decorrentes de um contrato de compra e venda de mercadorias ou de prestação de serviços entre um fornecedor e um devedor estabelecidos em estados diferentes.

Além disso, os países em que o fornecedor, o devedor e o factor possuem seus estabelecimentos devem ser países contratantes ou, quando não, o contrato de compra e venda de mercadorias ou de prestação de serviços e o contrato de factoring devem ser regidos pela lei de um estado contratante.

Nota-se, portanto, que, se nos depararmos com uma das situações anteriormente mencionadas, a Convenção de Ottawa será aplicável ao contrato de factoring, pois todos esses casos demonstram que se trata de uma operação no âmbito internacional.

Logo, o critério utilizado para que a Convenção de Ottawa possa ser aplicável remete ao lugar do estabelecimento dos sujeitos envolvidos no contrato de factoring ou, então, às regras de conflitos de leis.

Em vista disso, nota-se que o contrato de factoring assume a característica de internacionalidade não por referência ao contrato de factoring propriamente dito, mas em razão da compra e venda ou prestação de serviço internacional ao qual se encontra vinculado.

Assim sendo, depreende-se que a delimitação do âmbito de aplicação ao contrato de factoring internacional visava facilitar a ratificação da Convenção de Ottawa pelo maior número de Estados possível, pois não afeta, nem tampouco conflita com os ordenamentos jurídicos dos diversos estados.

Todavia, a princípio, pode-se afirmar que o factor e seus clientes estão submetidos a um duplo regime: o nacional, para a cessão de créditos e demais 
serviços envolvidos nas operações nacionais, e o das regras da Convenção de Ottawa para as operações internacionais.

Entretanto, faz-se necessário ressaltar que a delimitação do âmbito de aplicação do contrato de factoring internacional não implica na aplicação automática da Convenção de Ottawa, que, em seu artigo 3o, prevê a possibilidade de exclusão de sua aplicação através de acordo entre as partes do contrato de factoring ou, então, por parte daquelas que se encontram envolvidas no contrato de compra e venda de mercadorias ou de prestação de serviços ${ }^{43}$.

\section{CONCLUSÃO}

Ao analisar a evolução do contrato de factoring no âmbito do comércio internacional, nota-se que sua origem remonta ao período das colonizações, em que a intensificação das relações comerciais internacionais desempenhou um papel essencial para o desenvolvimento das negociações comerciais que envolvem esta modalidade contratual, bem como para o incremento pela sua opção por partes dos contratantes.

Não obstante, um dos maiores obstáculos enfrentados pelo contrato de factoring consiste na ausência de tipificação legal na maior parte dos ordenamentos jurídicos, dentre os quais o Brasil e Portugal. Assim, especialmente no âmbito internacional, em que o contrato encontra-se sujeito às regras de mais de um ordenamento jurídico, as dificuldades encontradas são ainda maiores.

Todavia, a despeito disso, cumpre asseverar que o contrato de factoring internacional proporciona uma série de vantagens para as partes contratantes, direta e indiretamente, devido à convergência e à intensa interdependência de seus interesses.

\footnotetext{
${ }^{43}$ Artigo 3. 1. A aplicação desta Convenção pode ser excluída:

(a) pelas partes no contrato de factoring; ou

(b) pelas partes no contrato de compra e venda de mercadorias em relação aos créditos cedidos no ato ou após a notificação por escrito do factor acerca desta exclusão.
}

Revista Brasileira de Direito Internacional, Curitiba, v.2, n.2, jul./dez.2005 
Com efeito, a variedade de serviços oferecidos pelo factor, de acordo com o que for convencionado pelas partes contratantes, possibilita a expansão e o fortalecimento das importações e exportações, especialmente para as pequenas e médias empresas, pois a atuação do factor propicia o desenvolvimento de atividades comerciais internacionais, com a possibilidade de acesso de produtos em novos mercados. Desta forma, este é um dos principais motivos que tem ensejado a opção das partes pelo contrato de factoring internacional.

Por outro lado, a possibilidade de atuação de um único factor permite que o contrato de factoring internacional possa ser assemelhado a uma operação de factoring no âmbito interno, em que a empresa exportadora relaciona-se somente com o export-factor, em razão das partes estarem situadas num mesmo país.

Além disso, a boa atuação do cliente também implica em vantagens para o factor, pois possibilita o desenvolvimento de suas atividades em diversos mercados.

Por conseguinte, as inúmeras vantagens apresentadas pelo contrato de factoring internacional afiguram-se mais do que suficientes para justificar o êxito que esta modalidade contratual tem experimentado no comércio internacional, principalmente na Europa.

Contudo, não se pode ignorar que o contrato de factoring internacional ainda necessita superar alguns obstáculos para que possa se desenvolver plenamente, tais como a falta de informações a respeito dos benefícios que proporciona para as partes envolvidas, bem como os elevados custos inerentes à sua operacionalização.

Da mesma forma, a atuação das Cadeias Internacionais de Factoring na divulgação do contrato de factoring também merece ser destacada, especialmente por terem sido elas as responsáveis pela criação e disseminação do import-export factoring ou sistema de dois factors, que atualmente consiste em uma das modalidades contratuais mais difundidas no comércio internacional. 
A Convenção de Ottawa sobre o factoring internacional, por sua vez, representa um marco importante para o factoring no âmbito do comércio internacional, pois unificou as regras materiais aplicáveis a esta modalidade de contrato, ainda que seja omissa em alguns aspectos que se afiguram importantes para o desenvolvimento desta modalidade contratual.

Por outro lado, mesmo para os países não signatários, a Convenção de Ottawa tem sido utilizada como parâmetro pelas partes em suas contratações.

Diante disso, pode-se afirmar que a Convenção foi bem sucedida, pois, desde o início, sua intenção era possibilitar a regulação dos aspectos referentes ao contrato de factoring internacional que se mostravam mais incertos e passíveis de serem unificados, o que ocorreu de forma exitosa.

Outrossim, nota-se que o legislador optou intencionalmente pela generalidade dos dispositivos quando da elaboração da sua elaboração, justamente a fim de possibilitar a aceitação pelo maior número de países, sem que isso implicasse na imposição de restrições por parte dos mesmos, o que, obviamente, impediria a execução dos seus objetivos.

Não obstante, a Convenção tem sido alvo de inúmeras críticas em razão das lacunas que apresenta na regulação do contrato de factoring internacional ${ }^{44}$.

Todavia, não se pode negar que a Convenção de Ottawa representou um grande avanço na uniformização das regras aplicáveis ao contrato de factoring internacional - a despeito de sua ratificação por um número inexpressivo de estados ${ }^{45}$-, pois constitui um importante ponto de referência e de interpretação a ser utilizado no âmbito do comércio internacional, inclusive pelos países não contratantes.

Desta forma, é incontestável que a Convenção de Ottawa pode e tem servido de base aos contratos de factoring internacional nos diversos ordenamentos jurídicos, na tentativa de possibilitar a uniformização das regras a serem aplicadas a esta modalidade contratual pelos diversos países.

\footnotetext{
${ }^{44}$ Porém, conforme anteriormente asseverado, a abrangência restrita da Convenção confere às partes contratantes a possibilidade de preencher suas lacunas, em observância ao princípio contratual da autonomia da vontade.

${ }^{45}$ Conforme anteriormente asseverado, até o presente momento, a Convenção de Ottawa foi ratificada por apenas seis estados. Vide nota 16.
}

Revista Brasileira de Direito Internacional, Curitiba, v.2, n.2, jul./dez.2005 


\section{EMENTÁRIO DE JURISPRUDÊNCIA COMPARADA}

BRASIL. Superior Tribunal de Justiça. Comercial - "Factoring" - Atividade não abrangida pelo sistema financeiro nacional - Inaplicabilidade dos juros permitidos às instituições financeiras. I - O "factoring" distancia-se de instituição financeira justamente porque seus negócios não se abrigam no direito de regresso e nem na garantia representada pelo aval ou endosso. Daí que nesse tipo de contrato não se aplicam os juros permitidos as instituições financeiras. É que as empresas que operam com o "factoring" não se incluem no âmbito do sistema financeiro nacional. II - O empréstimo e o desconto de tíitulos, a teor de art. 17, da Lei 4.595/64, são operações tipicas, privativas das instituições financeiras, dependendo sua prática de autorização governamental. III - Recurso não conhecido. Acórdão em Recurso Especial n. 119705/RS. Relator: Ministro Waldemar Zveiter. Data do julgamento: 07 abr. 1998. DJ, 29 jun. 1998, p. 161.

BRASIL. Superior Tribunal de Justiça. Falência. Nota promissória. Relações decorrentes do contrato de faturização. Precedente da Corte. 1. Se a empresa cedente dos títulos, em decorrência de contrato de factoring, deu causa a que os mesmos não pudessem ser recebidos, fica responsável pelo pagamento. 2. Afirmando o Acórdão recorrido que os títulos estavam viciados na origem e que a nota promissória foi emitida de acordo com o contrato celebrado entre as partes, afastando a hipótese de ter sido preenchida em branco, nada impede que possa servir para instruir pedido de falência. 3. Recurso especial não conhecido. Acórdão em Recurso Especial n. 330014/SP. Relator: Ministro Carlos Alberto Menezes Direito. Data do julgamento: 28 mai. 2002. DJ, 26 ago. 2002, p. 212.

BRASIL. Superior Tribunal de Justiça. Frustrada a expectativa do cessionário de títulos, por força de contrato de "factoring", de receber o respectivo valor, por ato imputável ao cedente, fica esse responsável pelo pagamento. Juros - Cômputo a partir da citação. Recurso parcialmente provido. Recurso Especial n. 43914/RS. Relator: Ministro Eduardo Ribeiro. Data do julgamento: 28 nov. 1995. DJ, 02 mar. 1996, p. 5402.

BRASIL. Superior Tribunal de Justiça. Recurso de "habeas corpus". Exame aprofundado de provas. Crime. Apelações privativas de instituições financeiras. "Factoring". Recurso improvido. 1. O empréstimo e o desconto de títulos, a teor do art. 17, da Lei 4.595/1964, são operações tipicas, privativas das instituições financeiras, dependendo sua prática de autorização governamental. 2. O "factoring" distancia-se da instituição financeira justamente porque seus negócios não se abrigam no direito de regresso e nem na garantia representada pelo aval ou endosso. 3. Nestas circunstâncias, imprópria e inadequada a via do "habeas corpus" para o pretendido debate acerca da atipicidade do fato, de modo a extremar as operações de "factoring" daquelas próprias das instituições financeiras, ou da ausência do elemento subjetivo. 4. Recurso ordinário improvido. Recurso Ordinário em Habeas Corpus n. 6394/RS. Relator: Ministro Fernando Gonçalves. Data do julgamento: 09 jun. 1997. DJ, 30 jun. 1997, p. 31083.

BRASIL. Superior Tribunal de Justiça. "Habeas corpus". Crime societário. Falta de justa causa e inépcia da denúncia. Atividades privativas de instituição financeira. "Factoring". Individualização da conduta. Habeas corpus indeferido. Acórdão em habeas corpus n $\mathrm{n}^{\circ} 7463-\mathrm{PR}$. Relator: Ministro Félix Fischer. Data do julgamento: 13 out. 1998. DJ, 22 fev. 1999, p. 112.

PORTUGAL. Supremo Tribunal de Justiça. 1. No contracto de factoring, a transmissão das facturas tem uma função estruturante do negócio, pois a cessão de créditos derivada daquele contrato é, ao fim e ao cabo, uma venda da facturação do aderente ou cedente. 2. Não constitui cedência plural (a mais que um factor), com prevalência da primeiramente notificada ( $\left.\operatorname{art}^{\circ} 584, \mathrm{CC}\right)$, a situação em que há uma primeira cedência de crédito indevidamente facturado, mas depois anulado através da emissão de uma nota de crédito de igual montante a favor do devedor, seguida da cedência a outro factor da nova factura, devidamente regularizada. Revista concedida. Acórdão em acção ordinária n. 2567/03. Relator: Quirino Soares. Data do julgamento: 04 mar. 2003.

PORTUGAL. Supremo Tribunal de Justiça. 1. O contrato de factoring consiste na transferência dos créditos a curto prazo do seu titular (cedente; aderente ao factor) para um factor (cessionário), derivados da venda de produtos ou prestação de serviços a terceiros (devedores cedidos). 2. Tal contrato reveste a natureza (não obstante a existência de naturais divergências na doutrina) de um negócio de promessa de cessão de créditos ou de cessão de créditos futuros, regendo-se pelas sua cláusulas e, subsidiariamente, pelas regras da cessão de créditos (artigos $577^{\circ}$ e seguintes do Código Civil). 3. Atenta a natureza jurídica

Revista Brasileira de Direito Internacional, Curitiba, v.2, n.2, jul./dez.2005 
da cessão de créditos, o crédito do cliente/aderente sobre o terceiro devedor constitui-se na esfera daquele, cedente, e só depois, em conformidade com o clausulado no contrato de factoring, se dá a transmissão para o cessionário (factor). 4. A cessão dos créditos pelo cedente produz efeitos em relação ao devedor desde que lhe seja notificada, mas nos precisos termos da comunicação. 5. Só pode considerar-se haver declaração negocial tácita, nos termos do artigo $217^{\circ}, \mathrm{n}^{\circ}$ 1, do Código Civil, quando os factos que revelam a vontade (e não a declaração) do declarante sejam inequívocos, na medida em que, conforme os usos da vida, haja quanto aos factos de que se trata toda a probabilidade de terem sido praticados com a significação negocial pretendida. Acórdão em acção declarativa ordinária n. 2660/02. Relator: Araújo Barros. Data do julgamento: 13 jan. 2005.

PORTUGAL. Supremo Tribunal de Justiça. 1. O contrato de factoring envolve, por um lado, a cedência pelo aderente ao factor de direitos de crédito com vista à realização por este da respectiva cobrança e, por outro, mediante contrapartida remuneratória, a cobertura do risco inerente àquela cobrança e a gestão ou o financiamento a curto prazo através da antecipação fundos. 2. Quem emite uma livrança em branco atribui a quem a entrega o direito de a preencher de acordo com as cláusulas convencionadas entre ambos, em jeito de delegação de confiança, incumbindo ao emitente a alegação e a prova do facto impeditivo do seu preenchimento abusivo. 3. O factor não viola o pacto de preenchimento da livrança envolvente do valor devido pelo aderente decorrente da execução do contrato de factoring, se nela inscrever esse débito de montante superior ao limite do adiantamento de fundos constante no clausulado daquele contrato. 4. A irregularidade decorrente da utilização para a livrança de um impresso próprio da letra de câmbio não afecta a sua validade como tal. 5. No domínio das relações imediatas, não obsta o princípio da literalidade inerente às livranças a que se interprete a vontade das partes, à luz da impressão do declaratário normal, como promessa de pagamento de determinada quantia, o texto expressante no seu vencimento pagará (ão) V.Ex ${ }^{a}$ (s) por esta única via de letra, aliás livrança. 6. À luz do princípio da boa fé, apurada a vontade do factor, do aderente e dos avalistas do último no sentido de garantir o pagamento pelo segundo ao primeiro do débito decorrente da execução do contrato de factoring, o preenchimento pelo primeiro aquele de uma livrança em vez da letra referida naquele contrato e no pacto de preenchimento não afecta a responsabilidade dos últimos pelo pagamento do valor da livrança. Recurso improvido. Acórdão em acção executiva para pagamento de quantia certa. Relator: Salvador da Costa. Data do julgamento: 27 mai. 2003.

PORTUGAL. Supremo Tribunal de Justiça. I - A actividade para bancária de "factoring" consiste na aquisição de créditos a curto prazo, derivados da venda de produtos ou da prestação de serviços nos mercados interno e externo. II - Em termos de natureza jurídica, o contrato de "factoring" deve ser qualificado como uma cessão de créditos, eventualmente futuros. III - A cessão produz efeitos em relação ao devedor, desde que lhe seja notificada, ou desde que ele a aceite. IV- O devedor pode opor ao cessionário todos os meios de defesa que lhe seria lícito invocar contra o cedente, com ressalva dos que provenham de facto posterior ao conhecimento da cessão. V - Os efeitos entre as partes (cedente e cessionário) estão dependentes do tipo de negócio que lhe serve de base. VI - Em relação ao devedor, que não tem de ser parte no contrato de factoring, a eficácia da cessão depende da respectiva notificação ou aceitação. Acórdão em acção ordinária n. 8252/03. Relator: Azevedo Barros. Data do julgamento: 27 mai. 2004.

PORTUGAL. Supremo Tribunal de Justiça. 1 - A cessão de créditos só produz efeitos, em relação ao devedor, desde que lhe seja notificada, ainda que extrajudicialmente, ou desde que ele a aceite. 2 - Quanto a terceiros, foi abolida, no regime do actual Código Civil, a limitação que constava do art. 789 do Código Civil de Seabra, no sentido de que a cessão também carecia de lhes ser notificada ou por eles aceite. 3 Um banco não tem o direito de dispor, unilateralmente e em seu benefício, de quantias nele depositadas, através do mecanismo extintivo da compensação, a menos que tal tenha sido convencionado com o seu cliente, titular da respectiva conta. 4 - A compensação não é admitida se houver prejuízo de direitos de terceiros, constituídos antes dos créditos se tornarem compensáveis. Revista negada. Acórdão no processo n. 2197/04. Relator: Azevedo Ramos. Data do julgamento: 29 jun. 2005.

PORTUGAL. Supremo Tribunal de Justiça. I - A nossa lei concebe o "factoring" como um contratoquadro organizatório, estruturalmente centrado em ulteriores vendas de crédito, com elementos do seguro e da prestação de serviços e com uma função predominantemente financeira. II - Tecnicamente atípico, apresenta os seguinte elementos estruturantes essenciais: - uma promessa de venda de créditos futuros; uma assunção de riscos; - a prestação de diversos serviços. III - A cessão financeira, ou factoring permite 
pagamentos antecipados, mas por conta de créditos cedidos, ainda não vencidos, não por créditos inexistentes - isso seria um mútuo puro e simples, fora da cessão financeira. IV - É irrelevante e sem qualquer validade a declaração unilateral do cedente de que revogou a cessão de créditos já cedidos. Revista negada. Acórdão no processo n. 6907/97. Relator: Fernandes de Magalhães. Data do julgamento: 06 out. 1998.

PORTUGAL. Supremo Tribunal de Justiça. I - Contrato de factoring é aquele pelo qual uma das partes (o cessionário financeiro, sociedade de factoring ou factor) adquire créditos a curto prazo que a outra parte (cliente, aderente ou fornecedor) tem sobre os seus clientes (devedores) derivados de venda de produtos ou de prestação de serviços nos mercados. II - Consiste pois tal contrato numa cessão de créditos duma das partes e na assunção por parte da sociedade de factoring dos riscos inerentes à respectiva cobrança, da eventual insolvabilidade do devedor e na concessão de financiamento ao cedente. III - Inter-partes, a cessão opera-se desde a conclusão do contrato independentemente da sua notificação ao devedor e sem necessidade de forma especial; porém, em relação ao devedor, a cessão só operará a partir da respectiva notificação (denuntiatio). IV - Se o primitivo credor ceder sucessivamente o mesmo direito a várias pessoas, prevalecerá a cessão primeiro notificada ao devedor ou aceite por este. Revista negada. Acórdão no processo n. 1016/98. Relator: Torres Paulo. Data do julgamento: 25 mai. 1999.

PORTUGAL. Supremo Tribunal de Justiça. I - O contrato de factoring consubstancia-se, por um lado, numa cessão de créditos e, por outro, na assunção por parte de sociedade de factoring, de três tipos de responsabilidades distintas: as dos riscos inerentes à futura cobrança dos créditos cedidos, a da eventual insolvabilidade do devedor e a da concessão de financiamento ao cedente. II - Tendo a devedora comunicado à cessionária o seu acordo expresso à cessão de créditos até certo montante, deve entender-se que renunciou à compensação na parte a ele excedente. Revista parcialmente concedida. Acórdão no processo n. 792. Relator: Roger Lopes. Data do julgamento: 06 fev. 1997.

PORTUGAL. Supremo Tribunal de Justiça. I. O contrato de "factoring" caracteriza-se pela transferência de créditos a curto prazo do seu titular (cedente, aderente) para um «factor» (cessionário), créditos esses resultantes da venda de produtos ou prestação de serviços a terceiros (devedores cedidos). II. Embora de natureza essencialmente comercial, assume tal contrato a natureza de uma cessão de créditos, sendo-lhe, como tal, subsidiariamente aplicável o regime jurídico contemplado nos $\operatorname{art}^{\circ} \mathrm{s} 577^{\circ}$ e ss do C.Civil. III. Nos casos em que o devedor-cedido seja o Estado ou outras pessoas colectivas de direito público, estes só poderão proceder a algum pagamento superior a 1.000.000\$00, em casos de dívida às instituições de previdência e da segurança social, depois de reterem o montante em débito até ao limite máximo de $25 \%$ do total concedido - DL 411/91. IV. Para que tal retenção não tenha lugar, torna-se necessário que, quer o aderente/cedente, quer o factor/cessionário, façam prova da regularização das dívidas à segurança social relativa aos últimos 180 dias. Revista negada. Acórdão em acção de simples apreciação negativa com processo ordinário n. 1346/02. Relator: Ferreira de Almeida. Data do julgamento: 05 jun. 2003.

PORTUGAL. Supremo Tribunal de Justiça. Revista negada. Acórdão em acção declarativa com processo ordinário. n. 5628/02. Relator: Oliveira Barros. Data do julgamento: 05 jun. 2003.

TRIBUNAL DE JUSTIÇA DAS COMUNIDADES EUROPÉIAS. Imposto sobre o Valor Acrescentado Sexta Directiva 77/388/CEE - Âmbito de aplicação - Factoring - Sociedade de factoring que compra créditos tomando a seu cargo o risco da falta de pagamento pelos devedores. Pedido de decisão prejudicial C-305/01. Finanzamt Groß-Gerau e MKG-Kraftfahrzeuge-Factoring GmbH. Relator: R. Schintgen. Acórdão proferido em 26 jun. 2003. JO C 184/9 02 ago. 2003.

\section{REFERÊNCIAS}

ASSOCIAÇÃO NACIONAL DAS SOCIEDADES DE FOMENTO MERCANTIL. http://www.anfac.com.br/jsp/institucional/quem.jsp. Disponibilidade: acesso em set. 2005.

BRASIL. Lei n. 10.646 de 10 de janeiro de 2002. Código Civil Brasileiro. 
BRASIL. Lei n. 5474 de 18 de julho de 1968. Dispõe sobre as Duplicatas, e dá outras providências.

BRASIL. Lei n. 556 de 25 de junho de 1850.. Código Comercial Brasileiro.

BRASIL. Lei n. 8981 de 20 de janeiro de 1995. Altera a legislação tributária Federal e dá outras providências.

BRASIL. Lei n. 9249 de 26 de dezembro de 1995. Altera a legislação do imposto de renda das pessoas jurídicas, bem como da contribuição social sobre o lucro líquido, e dá outras providências.

BRASIL. Lei n. 9430 de 27 de dezembro de 1996. Dispõe sobre a legislação tributária federal, as contribuições Para a seguridade social, o processo administrativo de consulta e dá outras providências.

BRITO, Maria Helena. O factoring internacional e a Convenção do UNIDROIT. Lisboa: Edições Cosmos, 1998.

BRITO, Maria Helena. Os contratos bancários e a Convenção de Roma de 19 de Junho de 1980 sobre a lei aplicável às obrigações contratuais. Separata da Revista da Banca, no 28 - outubro/dezembro 1993.

CALERO, Fernando Sánchez. El Contrato de Factoring em el Convenio Internacional de 1988. Jornadas sobre factoring. Madrid: Servicio de Publicaciones - Facultad de Derecho, p. 19/33, 1992.

CANADÁ. Convenção do UNIDROIT sobre factoring internacional, realizada em Ottawa entre 09 e 28 de maio de 1988.

CORDEIRO, António Menezes. Da cessão financeira (Factoring). Lisboa: Lex Edições Jurídicas, 1994.

CORDEIRO, António Menezes. Manual de Direito Bancário. 2. ed. Coimbra: Livraria Almedina, 2001.

DUARTE, Rui Pinto. Notas sobre o contrato de factoring. Novas perspectivas do Direito Comercial. Coimbra: Livraria Almedina, p. 141/158, 1988.

EIZAGUIRRE, José Maria. El factoring: la transmision de los créditos. Madrid: Servicio de Publicaciones - Facultad de Derecho, p. 135/151, 1992.

ESCOLA SUPERIOR DE TECNOLOGIA E GESTÃO DE BEJA. Reunião dos diplomas legais e atos jurisprudenciais mais pertinentes para a disciplina de Direito das Obrigações. http://www.estig.ipbeja.pt/ ac direito/dobriglegis.html. Disponibilidade: acesso em jul. 2005. 
EUROPA: O PORTAL DA UNIÃO EUROPEIA. www.europa.eu.int. Disponibilidade: acesso em jul. de 2005.

FACTORS CHAIN INTERNATIONAL. www.factors-chain.com. Disponibilidade: acesso em fev., ago. 2005.

FALCÃO, Guilherme J. Legislação que regula as empresas de fomento mercantil ("factoring") no Brasil, [Online]. http://www2.camara.gov.br/publicacoes/estnottec/tema12/pdf/111802.pdf.

Disponibilidade: acesso em ago. 2005.

GUILLAMÓN, Juan Roca. El contrato de factoring y su regulación por el Derecho Privado Español. Jaén: Editoriales de Derecho Reunidas, 1976.

HELLER FACTORING. http://www.hellerfactoring.pt/. Disponibilidade: acesso em ago. 2005.

INSTITUTO DE APOIO AS PEQUENAS E MÉDIAS EMPRESAS. http://www.iapmei.pt/index.php. Disponibilidade: acesso em fev., abr., ago., set. 2005.

INTERNATIONAL CHAMBER OF COMMERCE. http://www.iccwbo.org/. Disponibilidade: acesso em jun., ago. 2005.

INTERNATIONAL FACTORS GROUP. www.ifgroup.com. Disponibilidade: acesso em fev., ago. 2005.

ITÁLIA. Convenção sobre a lei aplicável às obrigações contratuais, realizada em Roma em 19 de Junho de 1980. Estabelece regras uniformes relativamente à lei aplicável às obrigações contratuais.

JIMÉNEZ, Maria Ángeles Sanches. El contrato de Factoring. CARAVACA, Alfonso L. Calvo; GÁNDARA, Luis Fernández de la. Contratos Internacionales, Madrid: Tecnos, 1997.

LLANTERO, Fernando Orbañanos. El contrato de factoring. Analisis pormenorizado de las cláusulas más frecuentes. Madrid: Servicio de Publicaciones - Facultad de Derecho, p. 83/101, 1992.

O PORTAL DOS CONSUMIDORES. http://www.consumidor.pt/pls/ic/doc?id=3018\&p acc=0\&plingua=1\&pmenu id= 1023. Disponibilidade: acesso em jul. 2005.

PORTUGAL. Decreto-Lei n. 171 de 18 de julho de 1995.

PORTUGAL. Decreto-Lei n. 298 de 31 de dezembro de 1992. Aprova o regime geral das instituições de crédito e sociedades financeiras. 
PORTUGAL. Decreto-Lei no 186 de 21 de agosto de 2002. Cria as instituições financeiras de crédito.

PRIBERAM INFORMÁTICA LDA., Língua Portuguesa On-Line. http://www.priberam.pt/dlpo/dlpo.aspx. Disponibilidade: acesso em ago. 2005.

PROCURADORIA GERAL DA REPÚBLICA. http://www.pgr.pt/. Disponibilidade: acesso em jul., ago., set. 2005.

REI, Maria Raquel Aleixo Antunes. Do Contrato-Quadro. Lisboa, 1997. $97 f$. Dissertação (Mestrado em Direito) - Curso de Mestrado em Ciências Jurídicas, Faculdade de Direito da Universidade de Lisboa.

RODRÍGUES, José Gallardo. El factoring como figura económico financeira. In Jornadas sobre factoring. Madrid: Servicio de Publicaciones - Facultad de Derecho, p. 39/61, 1992.

SOLÉ, Fernando Garcia. El Contrato de Factoring y sus Garantias: La crisis del contrato de Factoring. Aspectos procesales y concursales. Madrid: Servicio de Publicaciones - Facultad de Derecho, p. 161/185, 1992.

STRENGER, Irineu. Contratos Internacionais do Comércio. 4. ed. São Paulo: LTR, 2003.

SUPERIOR TRIBUNAL DE JUSTIÇA. www.sti.gov.br. Disponibilidade: acesso em ago., set. 2005.

SUPREMO TRIBUNAL DE JUSTIÇA. Disponível em www.stj.pt. Disponibilidade: acesso em mar., abr., jul., ago., set. 2005.

VASCONCELOS, Luís Miguel D. P. Pestana de. Dos contratos de cessão financeira (Factoring). In Boletim da Faculdade de Direito - Universidade de Coimbra. Coimbra: Coimbra Editora, 1999.

VINK, Gerhard. Desarrollo del factoring en el mundo. Madrid: Servicio de Publicaciones - Facultad de Derecho, p. 121/132, 1992. 